\title{
Psychosocial Conditions and Resilience Status of Street Children in Jimma Town
}

\author{
Berhanu Nigussie Worku $^{1 *}$, Dinaol Urgessa ${ }^{1}$, GetachewAbeshu ${ }^{1}$
}

\section{OPEN ACCESS}

Citation: Berhanu Nigussie Worku, Dinaol Urgessa, Getachew Abeshu. Psychosocial Conditions and Resilience Status of Street Children in Jimma Town. Ethiop J Health Sci. 2019;29(2):361. doi:http://dx.doi.org/10.4314/ ejhs.v29i2.8

Received: January 18, 2019

Accepted: January 21, 2019

Published: May 1, 2019

Copyright: (C) 2019 Berhanu Nigussie, et

al. This is an open access article distributed under the terms of the Creative Commons Attribution License, which permits unrestricted use, distribution, and reproduction in any medium, provided the original author and source are credited.

Funding: Nil

Competing Interests: The authors declare that this manuscript was approved by all authors in its form and that no competing interest exists.

Affiliation and Correspondence:

${ }^{1}$ Department of Psychology, College of

Education and Behavioral Sciences,

Jimma University, Ethiopia

*Email: brexnigussie83@yahoo.com berhanu.worku@uhasselt.be

\section{ABSTRACT}

BACKGROUND: Traditional research and practices focused on an investigation of risk factors to handle psychosocial problems street children faced while surviving on the street. However, more recently, attention has been given to how knowledge can be developed in the area to devise interventions that reflect the promotion of resilience as a means of achieving positive outcomes for the children. The purpose of this study was to explore the psychosocial conditions and resilience status of street children in Jimma Town.

METHODS: Explanatory sequential research design was employed. Out of 246 teenager street children, 137 were selected using simple random sampling. Questionnaire, interview guide and FGD probes were used in data collection. Mean and standard deviation, multiple regression analysis and Man Whitney $U$ T-test were used to analyze quantitative data; while discourse analysis was used to analyze qualitative data.

RESULTS: The result of multiple regression analysis indicated that anxiety significantly predicted resilience status, $b=.623, t$ (109) $=8.418, p<001$. Anxiety also explained a significant proportion of the variance in resilience status, $R^{2}=.388, F(112)=70.86, p<001$. Further, the result revealed that street children had slow growing resilience status in which boys were more resilient than girls.

CONCLUSION: Street children in Jimma Town faced various psychosocial challenges and had low resilience status. Thus, Jimma Town Women and Children Affairs Office ought to work to build resilience status of street children, in collaboration with different stakeholders in and around the town.

KEYWORDS: psychosocial conditions, resilience status, street children

\section{INTRODUCTION}

The phenomenon of street children is not new and neither is it restricted to certain geographical areas; rather it has been documented as far back as 1848 as a worldwide occurrence (1). The incidence is prevalent in both developed and developing countries (2). 
In 1922, there were at least seven million homeless children in Russia due to the devastation from World War I and the Russian Civil War (1). In the 1990s, many children moved onto the streets, with some being from the orphanages, while others were runaways from impoverished families. The twenty-first century presents a hostile face to many millions of children in many African countries. An increasing number of children are being forced to the streets as a result of poverty, abuse, torture, rape, abandonment or orphaned by AIDS (3).

The enormous problems (psychological, social, physical, and sexual abuses) faced by the street children in the last several years were reported by different scholars in different times, contexts and topic of diverse philosophy; but for several years, they were not in societies' program (4). Within the same trend, today's children are growing up in an increasingly stressful world. They are amongst the most vulnerable and marginalized members of society, often lacking access to food, shelter, healthcare, security and education (5). As everyone faces stress at some point, unfortunately, it is unrealistic to think that children can be shielded completely from experiencing stress (6). Many children on the street eat from garbage bins, sleep with little clothing, and are abused by others. These situations can result in dissociation that allows a child to almost remove himslf from the situation, to numb him from reality, and achieve separation between the body and the mind in that moment as a protective mechanism (7).

A comprehensive review indicated that street children experience high levels of hopelessness, vulnerability to depression and depressive symptoms (8). Since street children lack proper capabilities to secure a decent job, they face oppression, torture, insecurity and other problems while living on the streets (9). This has a detrimental effect on street children's development and often has serious psychosocial consequences, such as distrust in the children, lack of selfconfidence and negative interpersonal relationships. Because of their youthfulness, and specifically their lack of social power, children and adolescents are among the most severely affected by the aforementioned adverse circumstances (10).

However, some of these children possess structured system with gradual discovery of personal and unique abilities to successfully resilient from adverse conditions-psychological (depression, stress and anxiety) and social (social interaction, access to education and sexual exploitation) (11). Further, street children have future hopes, which can help them cope with poverty; and they have religious faith (12).

Even though the number of youth facing adversity and the number of adversities they face on the street are increasing, previous studies in this area did not document the psychosocial conditions and resilience status of these youths. Regardless of the agreement made between Ethiopia and the United Nations to end illiteracy rate on 2020, the number of street children dropped out of school, reran away and dwell on the street is alarmingly increading. Today's children who are growing up on the street would be tomorrow's adolescents and adults who can determine the destiny of themselves, their community and their country in either negatively (will be gangster, criminals, addicted to substances and will not be able to develop positive social interaction and skill) or positively - become productive society. Accordingly, in-depth investigation of the psychosocial conditions, challenges and level of resilience status would be of paramount importance to design appropriate intervention strategies for these children. This information is highly lacking in prior studies conducted on this subject.

For example, there are approximately 150,000 street children in Ethiopian urban areas, of which 40,000 reside in Addis Ababa. These children are mainly engaged in begging or working in the informal sector to earn their livelihood. Reports show that $70 \%$ of these children live in destitute families in slum areas (13). In South Western part of Ethiopia, Jimma Town is considered by many people, including teenagers, as cash crop area and trade center. As a result of this, children and adolescents migrate to the town for job opportunities; but many end up living on the street. This and other pushing factors lead to the gradual increment of street children in

DOI: http://dx.doi.org/10.4314/ejhs.v29i3.8 
the town from time to time. Most of them are confronted with harsh realities of psychological, social and economic challenges.

Besides, no matter how few NonGovernmental Organizations (NGOs) and Jimma Town Women and Children's Affairs Office have been trying to reunify these children to their original families, after few days, weeks or months, these children come back to the town and begin to live on the street. Some of these children receive limited support from NGOs operating in the town. Consequently, a number of children are still in a difficult situation and seek immediate attention.

Significant literatures which revealed resilience notions have generally been interpreted as conveying great optimism regarding the possibility of surviving adversity. Such optimism is well justified, but for this study, it is necessary to look at whether resilience is limited or large enough to maintain strong purpose in life. Considering the resilience status rather than making superficial intervention-informal education and rehabilitation that lack resiliencecould make an important contribution in curbing the adversities, and promoting adequate functioning competence, social system modification, and empowerment. Unfortunately, previous studies failed to address resilience status of street children.

Few previous studies on street children in the study area dealt with health and social problems of street children. However, this study focused on untapped aspects: psychosocial conditions and resilience status of street children.

The first objective of this study was to identify psychosocial conditions of street children in Jimma Town. The second objective examined the contributions of psychosocial conditions to resilience status of street children. The third and final objective of this study was to check gender differences in resilience status of street children.

\section{METHODS AND MATERIALS}

Explanatory sequential research design was employed. Quantitative research was employed first as a major approach and qualitative approach next.

A total population of the study were 965 street children who were on street and off street of four kebele's (Ginjo Guduru, N=98, Becho Bore, $\mathrm{N}=249$, Hirmata Merkato, $\mathrm{N}=438$, and Bosa Kitto, $N=107$ ) of Jimma Town that were selected purposively based on the availability of street children. The rest of the street children were found in other kebeles of Jimma Town, according to the Women and Children Affairs Office, 2010. Sample sizes of 137 on and off street children were selected randomly out of 246 teenagers target population. For $\leq 250$ target populations, at confidence level of $95 \%$ and margin of error $5 \%$, 132 is possible sample level (14).

Ethical clearance was received from the Ethical Committee of Research and Postgraduate Coordination Office of the College of Education and Behavioral Sciences of Jimma University. Permission to access the children was also obtained from Jimma Town Women and Children's Affairs Office. Consents for participation and publication of the findings were also obtained.

The researcher dictated inclusion-exclusion criteria as follows: (1) Children less than 13 years of age were excluded from the study; (2) children less than three months after run away were also excluded from the study since the researchers assumed that these children might not give the necessary information that could fit the research objectives and also they might not be mature enough to express their ideas. Items to measure resilience status were adapted from Ryff and Keye's (15) 6-point purpose in life resilience scale and changed to 4 point Likert scales. Four Likert scale items (Strongly agree, agree, disagree and strongly disagree) were used. The questionnaires were filled by data collectors by reading word for word for these children. Inclusion-exclusion processes were done by psychologist experts of Jimma Women and Children Affairs office and households of temporarily rented accommodations for they know more about children who stayed above three months on the street. Short term

DOI: http://dx.doi.org/10.4314/ejhs.v29i3.8 
training was given for these experts on how to get accurate data. Questionnaire regarding psychosocial and resilience status was employed by three researchers. Interview and focus group discussion were also conducted with expert moderators who had friendly relationship with these children. One hour and 10 minutes per child was dedicated to interview; whereas two hours per group discussion was used to conduct FGD.

Quantitative data obtained through questionnaires were analyzed using SPSS version 21. P-value was set to 0.05 and all tests were nondirectional. Descriptive techniques (mean and standard deviation) and multiple regression analysis were used. Regression assumptions were checked and all assumptions were satisfied. To know the effect size, coefficient of determination $\left(\mathrm{R}^{2}\right)$ was calculated. Because of the violation of assumptions of normality of outcomes and homogeneity of variance, Mann-Whitney U (instead of independent t-test) was used to determine the difference in resilience status between male and female street children. Cohen's coefficient (r) was also run to know the effect size of difference in male and female resilience status of street children. Data from interview and FGD was analyzed through discourse method of qualitative data analysis.

\section{RESULTS}

Psychosocial conditions of street children: Life on the street is characterized by various psychological factors. Table 1 depicts that street children in the study area experienced anxiety, depression, deprivation of basic social services and lack of social support. This shows that street children encountered anxiety 'most of the time' where as they experienced depression, basic social services and social support 'rarely'.

The results of the interview and the focus group discussion (FGD) also revealed that street children experienced anxiety in the form of uneasiness, fantasizing, threatening events and worry. Besides, they reported that they also feel worthless, guilty and hopeless about their lives. As these children responded during the interview and the FGD, whenever they think about their future, they worry and feel restless about their future that if they dwell long on street their future life would be less bright. FGD discussants forwarded their idea in this way:

Life on the street has nothing to prefer of it. Day in and day out, shame, guilt and worry about life is not far apart of us. When we get hungry, we eat leftover food called "bule" buying it for five birr from hotels, restaurants and inn. Moreover, we rarely sleep at home by paying 6 (ETB) per night. When we have no money we sleep in ditch, because, the policeman and high building custodians hit us if we go to sleep on the verandah. Most of the time in the midnight, we consternate as if the policeman or guarders come to hit us. As a result, when we left without getting money, we sniff mastish-glues-that makes us free from worry about life and also to forget any of our lost parts of life. Furthermore, no matter how it is too heavy, we carry a load so as to get money. In general, street life is very mind-numbing life condition that for if we stay long in this way we will have no bright future.

The result of the interview further depicted that street children in Jimma Town exposed to a wide range of violations of their rights such as denial of payment for the materials they carried and physical abuse. As the study comes crosswise, if street children do not submit money they get by working or begging on the street, streets adult and gangsters cut off their body (face and hands) by surgery blade, putting them at coercion physically. Moreover, key informants also indicated that after street children sniff glue, they run here and there without watching out for car, motor cycle, and any other vehicles and even they come and run into the speedily driving car.

DOI: http://dx.doi.org/10.4314/ejhs.v29i3.8 
Table 1: Psychosocial conditions of street life that street children experience.

\begin{tabular}{lrrl}
\hline Psychosocial conditions & $\mathrm{N}$ & Mean & Std. Deviation \\
\hline Anxiety & 114 & 2.7456 & .66870 \\
Depression & 114 & 2.3872 & .48556 \\
Basic social services & 114 & 2.4023 & .39528 \\
Social support & 114 & 2.1371 & .39667 \\
\hline
\end{tabular}

$($ Never $=1.00-1.75$, Rarely $=1.76-2.5$, Most of the time $=2.51-3.25$ and Always $=3.26-4.00)$

Psychosocial conditions contributions to the resilience status of street children: The contribution of psychosocial conditions to resilience status of street children was examined through multiple linear regression analysis. Predictor variables such as anxiety, stress, basic social service and social support were considered while data was analyzed.Table 2 shows the extent of the contribution of depression, basic social service and social support. As the result indicated, depression $(b=.118, \quad p=.107)$, basic social services, $(b=-.018, p=.81)$, and social support $(=b-.069, p=.35)$, had no significant contribution to resilience status of street children.

The results of the regression analysis indicated that anxiety significantly predicted resilience status, $b=.623, t(109)=8.418, p<.001$. Anxiety also explained a significant proportion of the variance in resilience status $R^{2}=388, F$ (112) $=70.86, p<.001$. Thus, about $38.8 \%$ of the variance in resilience status was explained by anxiety.
Data from street children's interview also supported that these children get troubled with policemen's and gangsters' maltreatment and abuse. In addition, these children reported that they worried about their life because of the multifaceted problems they face day in and day out. For instance, whenever these children get sick and are left with no money, no food to eat and have no one by their side, they stay in difficult situation till they get well.

Gender difference in resilience status of street children: So as to examine the extent of difference in resilience status between male and female street children, the Mann-Whitney U test was used (see Table 3). The result of the test showed a significant difference in resilience status between male and female street children, in which resilience status was greater for male street children $($ Median $=65)$ than for females $($ Median $=$ 55), $U=597.500, p<.001$. However, the effect size was small $(\mathrm{r}=-.33)$.

Table 2: Contribution of anxiety to resilience status of street children.

\begin{tabular}{lccll}
\hline Model & $\mathrm{R}^{2}$ & & $\mathrm{t}$ & $\mathrm{P}$-value \\
\hline Anxiety & .388 & .623 & 8.418 & .000 \\
Depression & & $.118^{\mathrm{b}}$ & .276 & .107 \\
social services & & $-.018^{\mathrm{b}}$ & -.236 & .814 \\
Social support & & $-.069^{\mathrm{b}}$ & -.934 & .353 \\
\hline
\end{tabular}

$\mathrm{R}^{2}$ coefficient of multiple determination, $\mathrm{b}$ regression coefficient, $\mathrm{t} t$-test statistic 
Table 3: Gender difference in resilience status

\begin{tabular}{cc}
\hline \multicolumn{2}{c}{ Resilience status } \\
\hline Mann-Whitney U & 597.500 \\
Wilcoxon W & 922.500 \\
$\mathrm{Z}$ & -3.539 \\
$\mathrm{r}$ & .33 \\
P-value & .000 \\
\hline
\end{tabular}

$r$ effect size

Data obtained through FGD also revealed that male street children attempted to do things by themselves. They also had moral compass to change their future and overcome their own problems without waiting for others' support; whereas female street children depended on others to get support.

\section{DISCUSSION}

Based on the major findings of the study, the discussion framed the themes along which the basic research questions were formulated. Street children faced varies psychosocial challenges while they were living on the street. Among these are the following: absence of basic social service and needs like food, clothes, secure sleeping places. qualitative study also scrutinized lack of access to services such as health, education and recreational activities, psychological restlessness, depression, anxiety and other psychosocial aspects as major challenges. Similar to this finding, a previous research showed that street children faced multiple challenges while they were living on the street (16). Another study reported that there was apparent lack of organized health and social services for street children; these affected their resilience status (17). Similarly, a study conducted by Ayub and his colleagues revealed that street children showed sadness, fear, anxiety, misery, despair, hopelessness, helplessness and suicidal ideation, which in turn lead to drug abuse and criminal activities (18). These aforementioned negative emotions and behaviors can also hammer the resilience status of these children.

Moreover, the qualitative part of this study identified that street children were exposed to physical abuse and substance abuse, particularly glue sniffing (commonly known as 'Mastish') that has addictive chemical component. In concur with this study, a prior study depicted that a large majority of the street children were addicted to different types of substances such as smoking and glue sniffing (19). Still, another previous study revealed that glue sniffing has immediate and long term devastating health consequences such as brain damage, paralysis, kidney and liver failure and eventually gateway drug for other drugs and risky practices, increased HIV/AIDS risk and death (20). Street children experienced multiple traumas such as neglect, maltreatment, psychological, physical and sexual abuse and, these multifaceted factors highly reduce the resilience of these children. Street children faced particularly anxiety (21). In addition, resilience status was greater for male street children in our study. Contrary to this finding, girls were more resilient than boys in adversity (22). For example, girls are more likely than boys to survive famines and epidemics. This gender difference in different contexts could be attributed to socio-cultural variables.

In conclusion, street children faced various psychosocial challenges such as absence basic needs and services like food, clothes, secure shelters, depression, anxiety, substance abuse, and labor exploitation. Anxiety had a significant contribution to resilience status than depression, and social conditions such as basic social service and social support. Even though these children did not have better access to basic social service and social support, they had promising naturally growing resilience status. There was a significant difference in resilience status between male and

DOI: http://dx.doi.org/10.4314/ejhs.v29i3.8 
female street children, in which resilience status was greater for male street children. Thus, prospects of street connected children, streetism and substance abuse, particularly glue sniffing, and strategies to build resilience are few areas suggested by for further studies.

\section{ACKNOWLEDGEMENT}

We greatlyappreciate all individuals who contributed to the successful accomplishment of this study. Particularly, we thank all the children who took part inthe present work. We are also grateful to Amanuel Tadesse and Israel Abaynehfor participating in the data collection.

\section{REFERENCES}

1. Elzahne S, Alida G, Herman S.The psychosocial circumstances and needs of street children.North West University, South Africa. 2017; 57(2):562-580.

2. Tadesse H. A study on street children in Dessie with specific reference to ADMAS child rehabilitation \& development project. Addis Ababa, Ethiopia, 2016.

3. Kopoka A. The problem of street children in Africa: International conference on street children and street children's health in east Africa. Dar-es-salaam: Tanzania, 2000.

4. Habtamu W, Arindam L. Livelihood of Street Children and the Role of Social Intervention: Insights from Literature Using Meta-Analysis: Child Development research. India: Burdwan, 2016.

5. Purna S. Reaching the marginalized- How to approach Inclusive Education. Dar es Salaam: Tanzania, 2009.

6. NCHE. Resilience in Children and Young People: The Bridge Child Care Development: London, 2007.

7. Barnes M, ChegeCh, Bustrum M, Girgius S, Caddell M. Kenyan Street Boys: The Effect of Individual Experiences on Psychological Well-Being. Azusa, Pacific University. AfricanJournal of Clinical Psychology. 2018; 01(02):1-16.
8. Woan J, Lin J, Auerswald C. A systematic review health status of street children and youth in low and middle income countries. Washington: America. Journal of Adolescent health, 2013:53:314-321.

9. Hai A. Problems Faced By the Street Children: A Study on Some Selected Places in Dhaka City: Bangladesh: International journal of scientific \& technology research.2014; 3(10):45-56.

10. Boyden J, Mann G. Children's risk, resilience, and coping in extreme situations', in Ungar: Pathways to resilience across cultures and contexts. University of Oxford, 2005; 3-25.

11. Abdelfatah I. Characteristics of street children: International relations students, 2012.

12. Mashicolo N. Understanding streetism from the street children's perspective: a qualitative study. Dissertation, North-West University, 2016; 1-169.

13. United Nation. Ethiopia Country Report. General condition of Ethiopian children: Addis Ababa, Ethiopia. 2014.

14. Cohen L., Mansion L, Morrison K. Research methods in education. New York: Routledge, 2011.

15. Ryff \& Keyes. Purpose in life resilience scale, 1995.

16. Mahderehiwot A. The experience of street children in the rehabilitation program of kirkos sub city: the case of drop in rehabilitation center project child space program: Addis Ababa, Ethiopia,2014.

17. Ayub T, Kumat D, Shora N. Psychosocial, demographic, health and educational characteristics of street children, 2015.

18. Myburgh C, Moolla A, Poggenpoel M. The lived experiences of children living of the streets of Hill brow: South Africa, 2015.

19. Nasir M, Siddiqui F. An analysis of causative factors which push and pull the children out of their home into the street world at Lahore. International Journal of Asian Social Science, 2017; 2:1508-1518. 
20. Gosa E. Glue sniffing street children of Addis Ababa: Narrative review of the literature. Addis Ababa, Ethiopia, 2017.

21. Derivois D, Hébert M, Amédée L, Karray A. Multiple traumas and resilience among street children. Haiti: Canada. Psychopathology of survival, 2018.
22. Hays B. When the going gets tough, women are more resilient than men. Washington, America, 2018.

DOI: http://dx.doi.org/10.4314/ejhs.v29i3.8 